\title{
Reflections of a Black woman physician-scientist
}

\author{
Rotonya M. Carr
}

Division of Gastroenterology, Perelman School of Medicine, University of Pennsylvania, Philadelphia, Pennsylvania, USA.

\section{My experience}

I am a Black woman hepatologist and hepatic lipid droplet biology physicianscientist. I have a nontraditional path as a researcher, having begun my career as a general internal medicine physician in a rural, medically underserved community. I ultimately chose a research career in hepatology because of the devastating consequences of end-stage liver disease that can be prevented by focusing on diagnosis and management of early stage disease. Investigating lipid droplet biology is perfect for this mission, as lipid droplet accumulation is often the first evidence of injury in many liver diseases.

Lipid droplet biology is a relatively recent area of science (compared with other organelle biology) and, as such, has a small cohort of researchers. In fact, in 2020, there are only 43 investigators who have active NIH R01/or R01 equivalent grants. For comparison, 525 investigators are funded for mitochondrial biology (1). When I overlay my lipid droplet focus with my other niches of alcoholic liver disease and nonalcoholic fatty liver disease, that number shrinks to 13. I do not know how many of us identify as Black women, but I suspect that I am the only one, as I have not met any other Black women faculty at our lipid droplet biology-focused scientific meetings.

My experience as "the only" or "one of few" is commonplace for Black women physician-scientists. Black women comprise $1.6 \%$ of clinical and nonclinical faculty at academic medical centers (AMCs) compared with $22.9 \%$ for White women $(2,3)$. Consequently, whether studying lipid droplets or cardiovascular outcomes, Black women physicianscientists are more likely than not to be an underrepresented demographic among our colleagues.

\section{Underrepresentation is pervasive in academia}

As Black women advance in academia, the landscape becomes even more stark. Of AMC faculty, $0.37 \%$ are Black women associate and full professors. Out of 2675 chairs of basic science and clinical departments, 10 are Black women (2 basic science and 8 clinical science) $(2,3)$. My own School of Medicine (University of Pennsylvania) faculty includes 77 Black women (out of approximately 2800 total members, $2.8 \%$ ), 34 of whom are either associate or full professors. Of these, 33 (1.2\% of total faculty) are researchers and one is a chair of a department. While these absolute numbers are concerning, more concerning is that strategies that have been successful in narrowing the gender gap in academic faculty positions in AMCs have had little, if any, effect on Black women in academic medicine (3-5).

There are multiple reasons for this persistent "race-gender gap"(6) among AMC faculty. Some factors include the low pool of Black women faculty candidates, faculty attrition, and research discrimination. In 2011, the NIH sounded the alarm for the low rate of NIH funding for Black scientists (7). Nine years later, this disparity persists, with Black researchers having an almost two-fold lower rate of funding compared with White researchers (8). The differences in funding rates cannot be explained by "education, citizenship, country of origin, training, employer characteristics, prior research awards, [or] publication record," because even after controlling for these factors, Black researchers are less likely to have their grants selected for discussion and, consequently, receive less NIH funding than both their nonminority and minority counterparts (7).

Forty-two percent of the funding disparity is explained by research bias during the selection of applications for discussion. Once discussed and scored, grants that receive

Conflict of interest: RMC has received research support from Intercept Pharmaceuticals.

Copyright: ( 2020 , American Society for Clinical Investigation.

Reference information: J Clin Invest. 2020;130(11):5624-5625. https://doi.org/10.1172/JCl144525.

fundable scores are funded at equivalent rates regardless of the race of the researcher (8). Grant subject matter is the greatest predictor of whether grants are discussed. Grants submitted by Black researchers most commonly include the terms socioeconomic, health care, disparity, lifestyle, psychosocial, adolescent, and risk, topics with funding rates ranging from approximately $11 \%-17 \%$. The least successful grants include the terms ova$r y$, fertility, and reproductive and only have a $7.5 \%$ success rate (8). Hence, because women comprise the majority of the principal investigators with active R01s that include ovary, fertility, or reproductive in the title (1), Black women researchers are at risk of experiencing funding disparities on the basis of both race and gender. In turn, these funding disparities can negatively impact promotion prospects for Black women and ultimately contribute to their attrition.

\section{Societal factors contributing to attrition}

For Black women researchers, challenges to one's academic productivity also come in the form of daily and deliberate navigation of the societal and institutional racism that impacts self and family. These experiences have resulted in many Black women leaving academia (9). For women researchers with children, the workbased stressors are often compounded by increased childcare and home responsibilities (10). For those of us who remain in academia, we have continued to negotiate that tension even while dealing with COVID-19-related losses in productivity (11) and helping institutions develop effective, sustainable antiracism policies in response to the social unrest that ensued after the killing of Mr. George Floyd. The adverse impact of all of these strains on the retention of Black women faculty is likely to be felt for years to come.

\section{Tangible solutions}

While institutions can develop initiatives aimed at increasing the recruitment and retention of Black women and oth- 
er minority faculty, the specific issue of research discrimination requires a unique approach. As a parallel, Black businesswomen comprise the fastest growing demographic of entrepreneurs, an increase of $164 \%$ since 2007 (12). However, despite their growing contribution to the business entrepreneurial landscape, Black women business owners are less likely to be granted access to sufficient capital compared with their nonminority counterparts, even after controlling for objective factors such as credit score (13). Just as business enterprises are beginning to counteract this discrimination with specific business-financing programs for Black women, AMCs and grant-funding institutions must use a similar targeted approach to address research discrimination. To start, the NIH and other funding institutions should analyze gender data according to race and ethnicity to understand just how wide the race-gender gap is for researchers. My attempts to access these data from publicly available databases were unsuccessful, causing me to wonder if these data exist at all. If such data exist, they should be made accessible so that the entire research community can engage in the solutions. Only after these data are known can funding agencies develop specific strategies to close the gap. While some solutions may involve allocating funds for this group of women, other solutions should focus on remediating the culture of research discrimination that leads to a lower value being placed on research topics that are more likely to be submitted by women and minorities.

Investing in the retention and promotion of Black women academics results in those Black women becoming role models for aspiring Black women researchers; as a result of this mentorship, the pool increases. Conversely, the loss of Black women from academia causes a profound sense of personal loss for Black students, trainees, and faculty. There is the loss of academic collaboration, loss of institutional talent, and loss of support systems. I personally know four Black women who have left academia in the past two years, and, as with any type of loss, the recovery from each loss becomes more difficult.

\section{Perspectives}

As a Black woman junior faculty member approaching midcareer status, I offer a perspective of someone whose own career has benefited both directly and indirectly from Black women researchers. Because we are few, these networks quickly become integral to our survival as academics. Increasingly, these networks include Black women who have decided to leave academia to begin other careers. Nevertheless, their journey and contributions outside of academia offer insight into what it takes to recruit, retain, support, promote, and sponsor Black women faculty within AMCs.

While I lean on my mentors to help me navigate how to revive my research program amidst the pandemic-related lab shutdown, I am acutely aware that what I do in this next phase of my career is not simply to promote my own research. I will also use this next phase to create and sustain opportunities for those who follow me - those for whom the simple act of seeing someone like them, who is an "only" or "one of a few," gives them a renewed sense of purpose and mission.

\section{Acknowledgments}

RMC is supported by NIH grants R01 AA026302 and P30 DK0503060.

Address correspondence to: Rotonya $\mathrm{M}$. Carr, 421 Curie Boulevard, 907 Biomedical Research Building, Philadelphia, Pennsylvania 19104, USA. Phone: 215.573.3933; Email: rotonya.carr@pennmedicine.upenn.edu.

1. NIH Research Portfolio Online Report Tools (RePORT). National Institutes of Health. Accessed September 29, 2020. https://project- reporter.nih.gov/reporter.cfm.

2. AAMC Faculty Roster: US Medical School Faculty. Association of American Medical Colleges. Accessed September 29, 2020. https://www. aamc.org/data-reports/faculty-institutions/ interactive-data/2019-us-medical-school-faculty.

3. Lautenberger D, Castillo-Page L. An overview of women full-time medical school faculty of color. AAMC: Analysis in Brief. 2016;16(4).

4. Pohlhaus JR, Jiang H, Wagner RM, Schaffer WT, Pinn VW. Sex differences in application, success, and funding rates for $\mathrm{NIH}$ extramural programs. Acad Med. 2011;86(6):759-767.

5. Ginther DK, Kahn S, Schaffer WT. Gender, race/ ethnicity, and National Institutes of Health R01 research awards: is there evidence of a double bind for women of color? Acad Med. 2016;91(8):1098-1107.

6. López N. Unraveling the race-gender gap in education: second-generation Dominican men's high school experiences. In: Kasinitz P, Mollenkopf JH, Waters MC, eds. Becoming New Yorkers: Ethnographies of the New Second Generation. Russell Sage Foundation; 2004:28-56.

7. Ginther DK, et al. Race, ethnicity, and NIH research awards. Science. 2011;333(6045):1015-1019.

8. Hoppe TA, et al. Topic choice contributes to the lower rate of NIH awards to African-American/black scientists. Sci Adv. 2019;5(10): eaaw7238.

9. Blackstock U. Why Black doctors like me are leaving faculty positions in academic medical centers. STAT. January 16, 2020. Accessed September 29, 2020.

10. Cardel MI, Dean N, Montoya-Williams D. Preventing a secondary epidemic of lost early career scientists: effects of COVID-19 pandemic on women with children [published online July 15, 2020]. Ann Am Thorac Soc. https://doi. org/10.1513/AnnalsATS.202006-589IP.

11. Myers KR, et al. Unequal effects of the COVID19 pandemic on scientists. Nat Hum Behav. 2020;4(9):880-883.

12. American Express. The 2018 state of womenowned businesses report: summary of key trends. Accessed September 29, 2020. https:// archive.mbda.gov/sites/mbda.gov/files/media/ files/2018/2018-state-of-women-owned-businesses-report.pdf.

13. Sheng E. This underfunded female demographic is launching the most start-ups in America, far from Silicon Valley. CNBC. February 25, 2020. Accessed September 29, 2020. https://www. cnbc.com/2020/02/25/underfunded-femaledemographic-is-launching-the-most-start-upsin-us.html. 